\title{
Gradhiva
}

GRADHIV

Revue d'anthropologie et d'histoire des arts

\section{Daniel Fabre et Anna Iuso (éd.), Les monuments sont} habités

Paris, Éditions de la Maison des sciences de l'homme, coll. «Cahiers d'ethnologie de la France » 24, 2009, 336 p.

\section{David Berliner}

\section{(2) OpenEdition Journals}

Édition électronique

URL : http://journals.openedition.org/gradhiva/2099

DOI : 10.4000/gradhiva.2099

ISSN : 1760-849X

Éditeur

Musée du quai Branly Jacques Chirac

Édition imprimée

Date de publication : 18 mai 2011

Pagination : 227-228

ISBN : 978-2-35744-042-5

ISSN : 0764-8928

Référence électronique

David Berliner, «Daniel Fabre et Anna luso (éd.), Les monuments sont habités », Gradhiva [En ligne], 13 | 2011, mis en ligne le 18 mai 2011, consulté le 21 septembre 2020. URL : http://

journals.openedition.org/gradhiva/2099; DOI : https://doi.org/10.4000/gradhiva.2099

Ce document a été généré automatiquement le 21 septembre 2020.

(c) musée du quai Branly 


\section{Daniel Fabre et Anna Iuso (éd.), Les monuments sont habités}

Paris, Éditions de la Maison des sciences de l'homme, coll. « Cahiers d'ethnologie de la France » 24, 2009, 336 p.

\section{David Berliner}

\section{RÉFÉRENCE}

Daniel Fabre et Anna Iuso (éd.), Les monuments sont habités. Paris, Éditions de la Maison des sciences de l'homme, coll. « Cahiers d'ethnologie de la France » 24, 2009, $336 \mathrm{p}$.

1 Les recherches anthropologiques sur le patrimoine sont florissantes aussi bien en France qu'en Italie. Voilà ce que révèle ce très bel ouvrage collectif édité par la Maison des sciences de l'homme, et qui est le résultat d'une collaboration de longue haleine entre des institutions françaises et italiennes autour de questions patrimoniales. En particulier, comme le rappelle Christian Hottin dans sa préface, ce genre de recherches s'est développé dans les milieux universitaires français depuis les années 1990, entraînant la fondation de centres et le lancement de programmes d'études, ainsi que l'organisation de colloques - tel celui dont ce recueil de textes est l'aboutissement -, autant d'actions scientifiques qui ont contribué à édifier un véritable paradigme en la matière.

Outre le fait qu'il rassemble chercheurs français et italiens, la particularité de ce volume est de mettre en lumière la manière dont les habitants d'un lieu patrimonialisé, ceux qui vivent à l'intérieur ou à ses côtés, font usage d'un monument. Les auteurs dévoilent «la multiplicité des usages profanes » (p. 25), les « attitudes de résistance », de "retrait sceptique ", d'« attention à éclipses ", d'ironie, ou, en sens inverse, «les tactiques locales d'appropriation»(p.26), ce que Daniel Fabre appelle, dans son introduction éclairante, «l'effet Gavroche ", à la suite du héros de Victor Hugo habitant un éléphant sur la place de la Bastille, qui constitue une «allégorie de l'habitant du monument » (p. 26). 
3 Par-delà leur diversité, les articles présentés dans ce recueil sont structurés autour de plusieurs idées centrales aux études sur le patrimoine. D'abord, tous s'accordent à décrire la métamorphose patrimoniale, ce processus par lequel des lieux souvent pauvres et «déclassés " se sont vus transformés en des espaces "classés » avec leurs habitants, et la perception de cette requalification par ces mêmes habitants du lieu. Qu'il suffise, par exemple, de penser à la cité de Carcassone (texte de Christiane Amiel), jadis habitée par les tisserands les plus misérables puis rénovée et désormais «touristifiée »; aux trulli des Pouilles (Anna Iuso), taudis insalubres devenus sites du patrimoine mondial en 1996 ; et aux Sassi de Matera (les trois textes complémentaires de Fernandino Mirizzi, Amergio Restucci et Dorothy Louise Zinn), ces habitations troglodytes, « honte nationale » vidée de ses habitants dans les années 1950, et ensuite transformée petit à petit en un monument ethnologique et artistique aujourd'hui consacré par l'Unesco. À cet égard, la plupart des textes réunis montrent le «désajustement» (pour reprendre le terme de Nathalie Heinich) qui existe entre le regard profane et celui des experts en rénovation et des élites locales. Dans le centre historique de San Marco en Campanie (Valeria Siniscalchi), les architectes ont utilisé la pierre, alors que celle-ci est vue comme un symbole d'inconfort et de pauvreté par les habitants qui raffolent, pour leur part, du crépi, signe de noblesse. À Matera, ceux qui ont jadis habité les Sassi restent "allergiques à toute valorisation artistique et historique " des lieux (p.96), et ne sont pas nostalgiques des conditions de vie insupportables d'antan.

4 Sur ce terrain, le rôle joué par les intellectuels patrimonialistes de la culture, « acteurs du renouveau » patrimonial (p.96), est prépondérant. Comme le montre Dorothy Zinn, Le Christ s'est arrêté à Eboli de Carlo Levy a contribué à l'objectification patrimoniale des Sassi, tandis qu'à Bernalda dans la Basilicate (texte de Rosa Parisi), des intellectuels locaux, historiens et archéologues réécrivent avec succès l'histoire de la ville en y inscrivant une hellénité fondatrice autour du site archéologique de Métaponte, s'efforçant en parallèle de retrouver dans des pratiques rituelles locales «les survivances d'une antique culture grecque»(p. 244). Chez les Dogons du Mali, seul exemple ethnographique tiré d'un contexte ni italien ni français, Gaetano Ciarcia montre à quel point la littérature érudite, notamment ethnologique d'inspiration griaulienne, a joué un rôle majeur dans le processus de valorisation patrimoniale. Dans tous les cas, qu'il s'agisse d'historiens, d'ethnologues, d'artistes, d'hommes politiques, de touristes ou de managers américains (comme à San Marco), la présence de nouveaux médiateurs avec lesquels les habitants du lieu doivent désormais interagir caractérise les scènes patrimoniales étudiées. Depuis la saline royale d'Arc-et-Senans (Alain Chenevez) jusqu'aux Sassi de Matera, il est frappant de noter l'omniprésence de l'Unesco, acteur aujourd'hui incontournable de la patrimonialisation, et qui produit un phénomène que Daniel Fabre nomme le "surclassement ", "confirmant l'entrée en scène locale de nouveaux groupes d'habitants et d'usagers du monument » (p. 44). En effet, les scènes patrimoniales tendent à se complexifier et leurs médiateurs à devenir multiples. Tourisme, relecture de l'histoire, repeuplement, spéculations économiques, mais aussi rivalités politiques, comme l'indique très justement l'article de Dino Palumbo à propos du Val de Noto, où le patrimoine devient un argument dans les luttes identitaires locales (comme c'est également le cas pour les trulli). Bref, et c'est bien ce que montrent pertinemment les textes réunis dans ce volume, avec la patrimonialisation surgissent de nouveaux conflits et de nouveaux enjeux dont les effets sont, pour le meilleur et pour le pire, très réels pour les habitants du lieu. 


\section{AUTEURS}

DAVID BERLINER

David.Berliner@ulb.ac.be 